\title{
SMOS REFLEX 2003: L-Band Emissivity Characterization of Vineyards
}

\author{
Mercè Vall-llossera, Member, IEEE, Adriano Camps, Senior Member, IEEE, Ignasi Corbella, Member, IEEE, \\ Francesc Torres, Member, IEEE, Núria Duffo, Member, IEEE, Alessandra Monerris, Student Member, IEEE, \\ Roberto Sabia, Student Member, IEEE, Daniel Selva, Carmen Antolín, Ernesto López-Baeza, Joan Ferran Ferrer, \\ and Kauzar Saleh
}

\begin{abstract}
The goal of the Soil Moisture and Ocean Salinity mission over land is to infer surface soil moisture from multiangular L-band radiometric measurements. As the canopy affects the microwave emission of land, it is necessary to characterize different vegetation layers. This paper presents the Reference Pixel L-Band Experiment (REFLEX), carried out in June-July 2003 at the València Anchor Station, Spain, to study the effects of grapevines on the soil emission and on the soil moisture retrieval. A wide range of soil moisture (SM), from saturated to completely dry soil, was measured with the Universitat Politècnica de Catalunya's L-band Automatic Radiometer (LAURA). Concurrently with the radiometric measurements, the gravimetric soil moisture, temperature, and roughness were measured, and the vines were fully characterized. The opacity and albedo of the vineyard have been estimated and found to be independent on the polarization. The $\tau-\omega$ model has been used to retrieve the SM and the vegetation parameters, obtaining a good accuracy for incidence angles up to $\mathbf{5 5}^{\circ}$. Algorithms with a three-parameter optimization (SM, albedo albedo, and opacity) exhibit a better performance than those with one-parameter optimization (SM).
\end{abstract}

Index Terms-L-band microwave radiometry, soil moisture, vineyards.

\section{INTRODUCTION}

$\mathbf{L}$ -BAND passive microwave remote sensing has proved to be useful to monitor soil moisture over land surfaces. The Soil Moisture and Ocean Salinity (SMOS) mission was selected by the European Space Agency (ESA) to provide soil moisture and sea surface salinity global coverage measurements with three-day revisit time [1]. Over land, SMOS aims at providing global maps of soil moisture with a ground resolution better than $50 \mathrm{~km}$ and with volumetric humidity accuracy better than $0.04 \mathrm{~m}^{3} / \mathrm{m}^{3}$. There is a strong interest in studying the contribution of vegetation to soil surface emission at L-band, especially for canopies where only a limited number of studies have been conducted (e.g., [2]). The SMOS Reference Pixel L-Band Experiment (SMOS REFLEX) 2003 is the first of a set of field cam-

Manuscript received April 27, 2004; revised December 20, 2004. This work was supported in part by the Spanish Comisión Interministerial de Ciencia y Tecnología (CICYT), in part by the European Union FEDER under Grant TIC 2002-04451-C02-01, and in part by CICYT under Grants ESP2001-4524-PE and ESP2001-4525-PE.

M. Vall-llossera, A. Camps, I. Corbella, F. Torres, N. Duffo, A. Monerris, R. Sabia, and D. Selva are with the Universitat Politècnica de Catalunya (UPC), E-08034, Barcelona, Spain (e-mail: merce@tsc.upc.edu).

C. Antolín and J. F. Ferrer are with the Desertification Research Center (CIDE), E-46170 Albal, Spain (e-mail: m.carmen.antolin@uv.es).

E. López-Baeza and K. Saleh are with the Universitat de València (UV), E-46100, Burjassot, Spain (e-mail: ernesto.lopez@uv.es).

Digital Object Identifier 10.1109/TGRS.2005.844102 paigns devoted to the characterization of a large area with few land uses, most of them vineyards, that could be a suitable reference pixel for SMOS ground calibration/validation. The main goal of this field experiment was the study of the brightness temperature $\left(T_{B}\right)$ dependence on soil moisture (SM) and observation angle, as well as the characterization of the vegetation layer. This paper describes the SMOS REFLEX 2003 field experiment and presents some results of the data processing.

\section{FIELD EXPERIMENT DESCRIPTION}

SMOS REFLEX 2003 took place from June 30 to July 10, 2003 at the València Anchor Station (VAS), Valencia, Space $\left(39^{\circ} 33^{\prime} \mathrm{N}, 1^{\circ} 17^{\prime} \mathrm{W}\right)$; see Fig. 1 and [3]. During the experiment period, the weather was very dry and warm. In order to get a wide range of soil moisture values, the field was irrigated twice (on July 1 and again on July 4, that is, the second and fifth days of the experiment), and it was then left to dry out. Hence, two complete measurement cycles (from saturated wet soil to completely dry soil) were performed. The first of them was shorter than the second (thee days in front of seven days) because the high temperatures and strong winds recorded at the beginning of the experiment dried the land much faster. Concurrently with the radiometric measurements, the gravimetric soil moisture, the temperature, and the roughness were measured, and the vines were fully characterized (water content, grapevine size, branches distribution, etc.). This section presents a description of all the tasks performed during the field campaign.

\section{A. Radiometric Measurements}

The radiometric observations were acquired with the Universitat Politècnica de Catalunya's (UPC) L-Band Automatic Radiometer (LAURA), which is a dual-polarization radiometer working at $1.4 \mathrm{GHz}$. Its $3-\mathrm{dB}$ beam width is $20^{\circ}$; the main beam efficiency is $95.2 \%$; and the radiometric sensitivity is approximately 0.5 [4]. LAURA was designed and implemented by the UPC team in 2000 to be used in a set of field experiments before the launch of SMOS. It has already been used in the Wind and Salinity Experiment (WISE) 2000 and 2001 and the Foam, Rain, Oil Slicks, and GPS (FROG) 2003 field experiments, [4]-[6].

During SMOS REFLEX 2003, LAURA was mounted on the top of a crane placed on a path between vineyards (Fig. 2). The antenna was oriented to the west, and its look direction was perpendicular to the tillage direction of the plot. Fig. 3 schematically shows the settlement of the site under study. The vines, represented by a circle with a dot inside, are distributed 


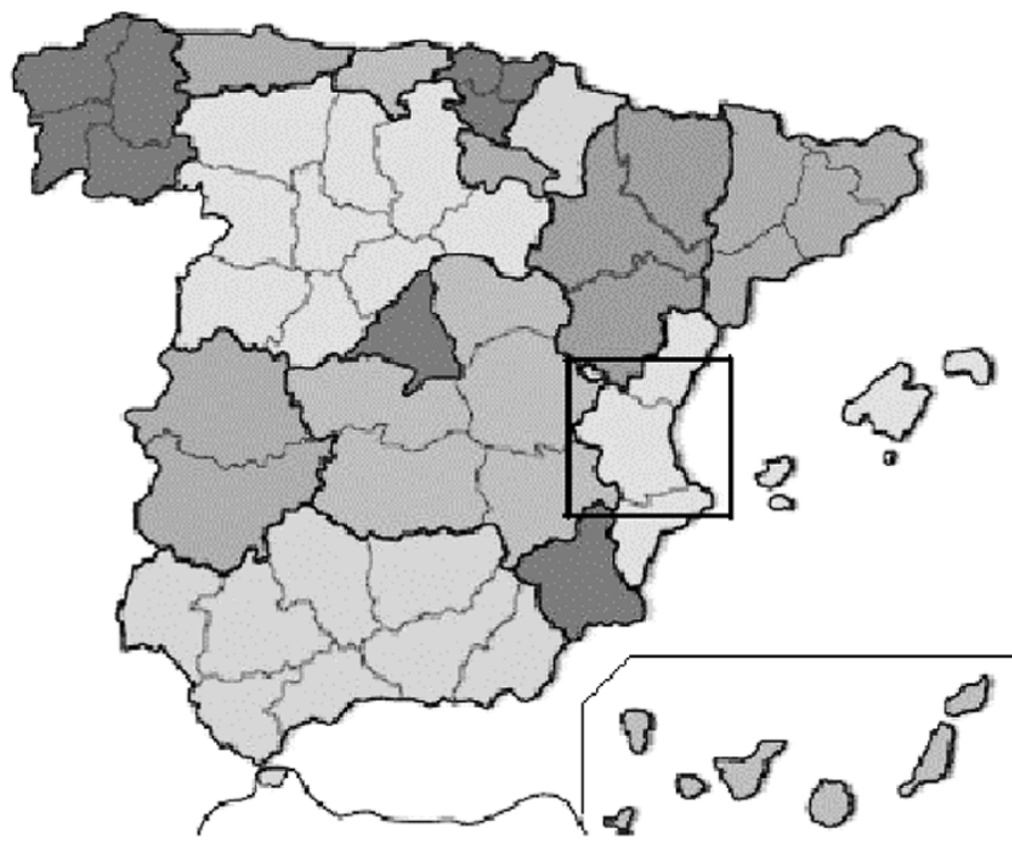

(a)

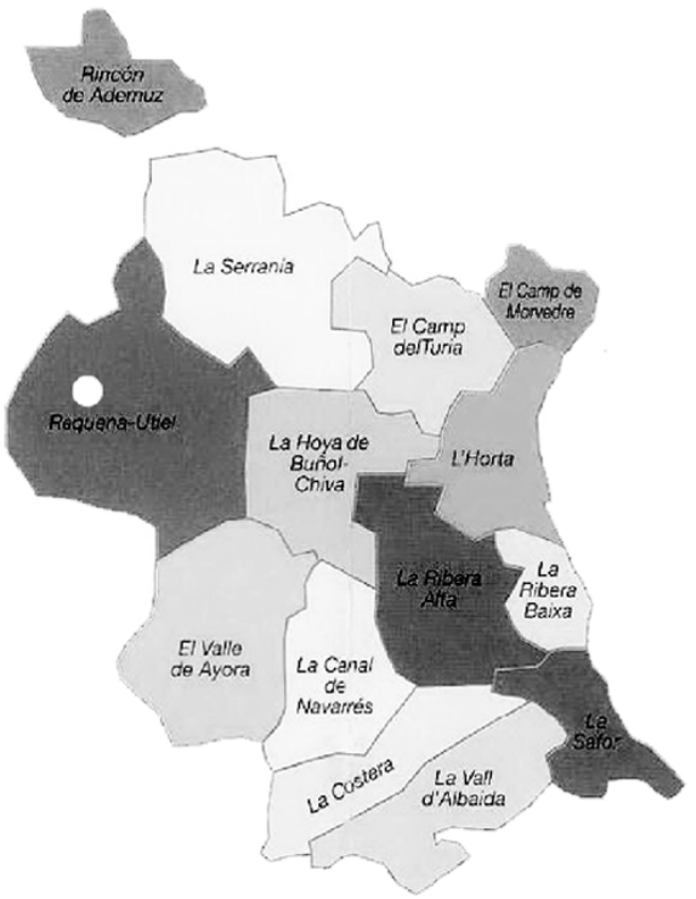

(b)

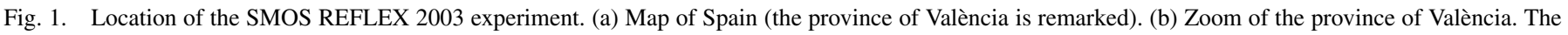
València Anchor Station is signaled with a white dot.

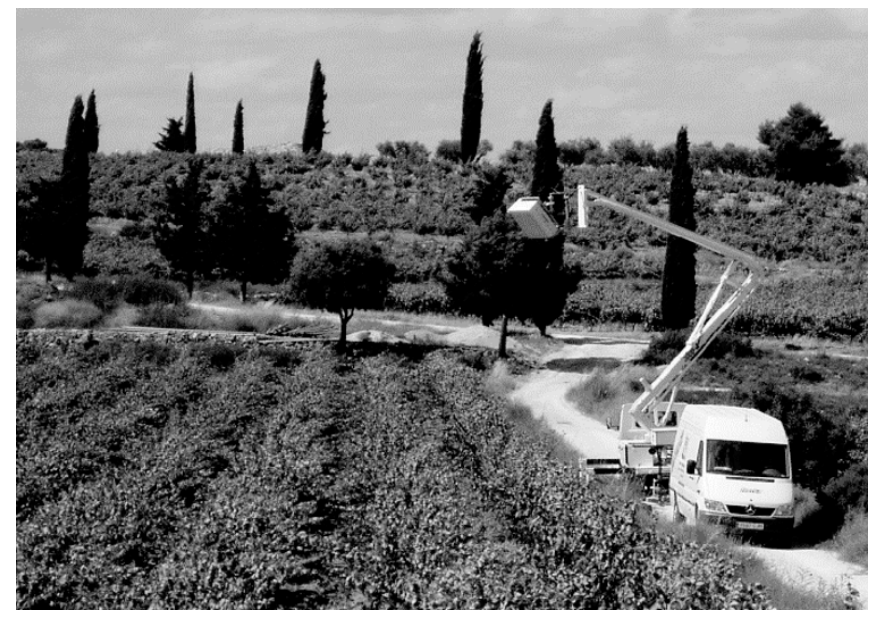

Fig. 2. Crane with the radiometer LAURA (west look direction) was placed on a path between two vineyards.

along rows parallel to the path, and are separated $1.5 \mathrm{~m}$; in each row plants are separated $2.5 \mathrm{~m}$ and located at $x(\mathrm{~m})=$ $\{-12.5,-10,-7.5,-5,-2.5,0,2.5,5,7.5,10,12.5,15\}$. Radiometric observations at nine incidence angles $\left(\theta\right.$, from $25^{\circ}$ to $65^{\circ}$ in $5^{\circ}$ steps $)$ and seven azimuth angles $\left(\phi\right.$, from $-45^{\circ}$ to $45^{\circ}$ in $15^{\circ}$ steps, being $\phi=0$ the direction perpendicular to the tillage) were carried out daily from 9.30 P.M. to 4 A.M. Therefore, a dataset composed of $9 \times 7$ observations at both vertical and horizontal polarizations was acquired every night. Hereafter, the dataset acquired each night is referred to as sequence (as the field campaign lasted 11 days, 11 sequences were registered). The number of the sequence is coincident with the day of experiment. At each orientation, LAURA was pointing to each

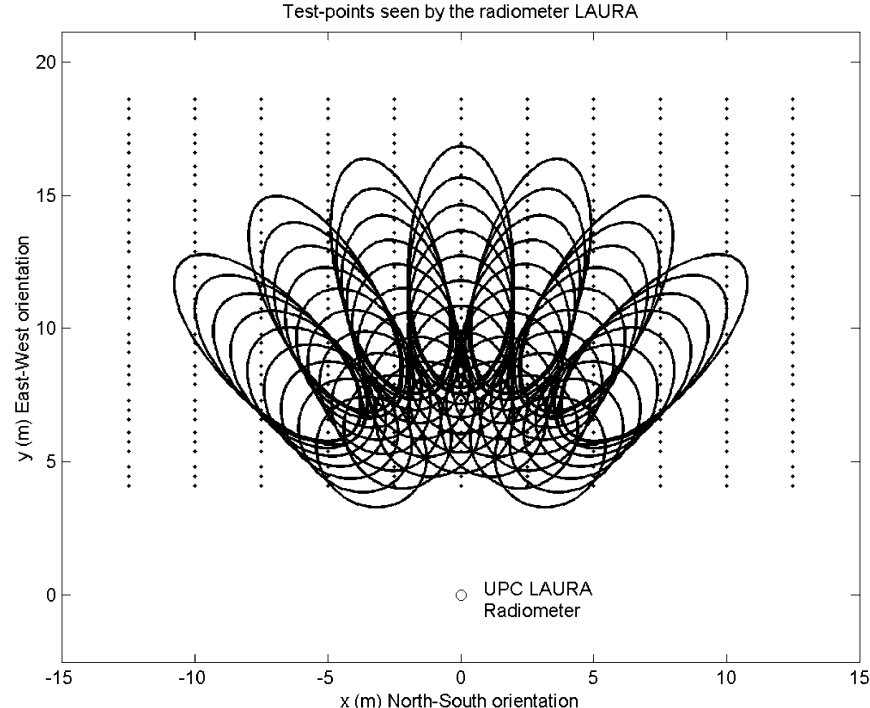

Fig. 3. Radiometer was oriented to the west ( $y$ axis), and its look direction was perpendicular to the tillage direction of the vineyard ( $x$ axis). The ellipses indicate the footprint of the radiometer for each observation position. The circles with dots inside indicate the location of the vines, and the dots correspond to gravimetric soil moisture samples.

target during $180 \mathrm{~s}$, with a sampling period of $1 \mathrm{~s}$. The ellipses plotted in Fig. 3 show the 63 footprints at half-power for each sequence (each footprint corresponds to a direction of observation). The ellipses are not all the same shape and size; in fact, the major axis increases with the incidence angle, while the minor axis is kept constant by changing the radiometer height for each incidence angle. 


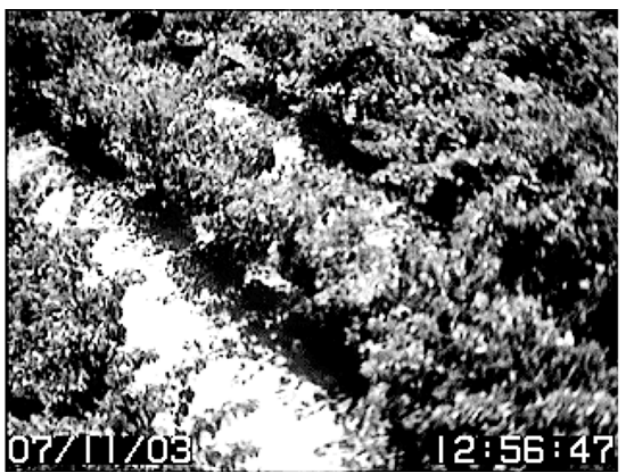

(a)

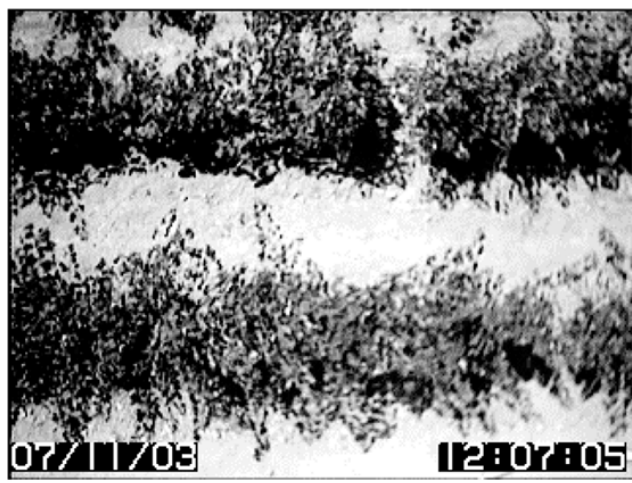

(b)

Fig. 4. Pixels captured by a video camera at (a) $\theta=60^{\circ}$ and $\phi=25^{\circ}$ and (b) $\theta=60^{\circ}$ and $\phi=0^{\circ}$.

Besides, a video camera pointing to the radiometer boresight was used to determine the fraction of soil covered by vegetation in each spot. Fig. 4 shows two images captured at two different positions: Fig. 4(a) $\theta=60^{\circ}$ and $\phi=25^{\circ}$ and Fig. 4(b) $\theta=$ $60^{\circ}$ and $\phi=0^{\circ}$. As can be appreciated, vegetation coverage depends on the direction of observation.

During the experiment, a set of measurements were taken so as to calibrate the instrument: 1) hot and cold load calibration, to obtain the first and second Stokes' parameters, and 2) correlated and uncorrelated noise injection calibration, to compensate the correlator errors and determine the third and fourth Stokes' parameters. Eccosorb slabs placed just in front of the antenna at ambient temperature were used as hot targets. The cold target was obtained by measuring the sky radiation through reflection on a metallic plate. ${ }^{1}$ The downwelling brightness temperature was computed from the antenna orientation and the measured antenna pattern, the geographical coordinates and the date and time, as well as the galactic noise map at $1420 \mathrm{MHz}$. It was found to be between 5 and $9 \mathrm{~K}$.

\section{B. Soil Characterization}

When SMOS REFLEX 2003 began, the soil was completely dry because neither rain nor irrigation had moistened the area for

\footnotetext{
${ }^{1}$ The validity of the hot and cold calibration measurements was assured with controlled experiments. The first one consisted in placing LAURA pointing to the eccosorb slabs in the UPC anechoic chamber. Measurements agreed well with the ones obtained during the hot load calibration period at the field campaign site. The second experiment consisted in measuring the sky pointing directly to the sky and through a reflection on a metallic plate. Both measurements were in agreement as well.
}

a long period. Dots in Fig. 3 represent the soil moisture sampling points: one sample under each grapevine and five samples between them (from row to row). These measurements were taken with Delta-T ThetaProbe sensors, which were previously calibrated for the type of soil under study. These sensors provided an average value from surface to 6-cm depth. Even though the field was irrigated uniformly, different values of moisture were measured because of surface inhomogeneities and variations on the compactness of the terrain due to plough and roots distribution.

A set of sensors were buried in the field to measure the soil temperature at the surface and 5, 10, 15, 20, and $40 \mathrm{~cm}$ deep. Due to technical problems, there is no soil temperature data available for sequences 7 and 8 , and the data at 5-cm depth was only acquired the first four days of experiment. The atmospheric temperature, pressure, and relative humidity were registered by the VAS meteorological station.

Fig. 5 shows the evolution of the atmospheric and the soil temperature data acquired in the vineyard for two days: a case of soil irrigated until saturation [Fig. 5(b), day 5 of experiment, from July 4 at noon until July 5 at noon] and a case of completely dry soil [Fig. 5(a), day 4 of experiment, from July 3 at noon until July 4 at noon]. In both cases, the radiometric measurements were held only from 9:30 P.M. of one day to 4 A.M. of the following day. Large atmospheric temperature gradients are registered in this area and for this time of the year. This fact was especially important in July 1, when the atmospheric temperature reached $38{ }^{\circ} \mathrm{C}$ at day-time and $14{ }^{\circ} \mathrm{C}$ at night. The difference between the atmospheric and the soil surface temperatures is larger when the soil is wet [up to $3{ }^{\circ} \mathrm{C}$ within a measurement period; Fig. 5(b)] than when the soil is dry [Fig. 5(a)]. The underground temperature stays quite constant with time and depth during the whole experiment. When the soil is wet, the penetration depth is small and the most important contribution to the effective soil temperature is due to the soil surface temperature. If the soil is dry, the wave propagates a larger distance through the soil layer and temperatures at various depths must be considered. An effective soil temperature has been computed taking these facts into account: the soil temperature has been assumed to be equal to the surface temperature when the soil is almost saturated, and in the other cases, an average (dependent on the soil wetness) of temperatures at the soil surface at $5-\mathrm{cm}$ depth (when measurements were recorded) and at 10-cm depth was computed.

Finally, some roughness measurements were carried out and the standard deviation of the terrain height was found to be $2.4 \mathrm{~cm}$.

\section{Vegetation Characterization}

SMOS REFLEX 2003 took place on a vineyard of tempranillo variety. The canopy was parameterized by measuring different parts of 11 test vines. The water content (WC) per compartment of a full plant per unit area was found to be 9-10 $\mathrm{kg} / \mathrm{m}^{2}$. Results of the characterization are detailed in Fig. 6(b) and Table I. The values make evident that these vines are taller than others in the Mediterranean region (medium height of $1.63 \mathrm{~m}$ and medium width of $1.45 \mathrm{~m}$ ). The leaf area index (LAI) was measured in different locations of the plot using a LAI-LICOR2000 sensor. Fig. 7 shows the mean value 


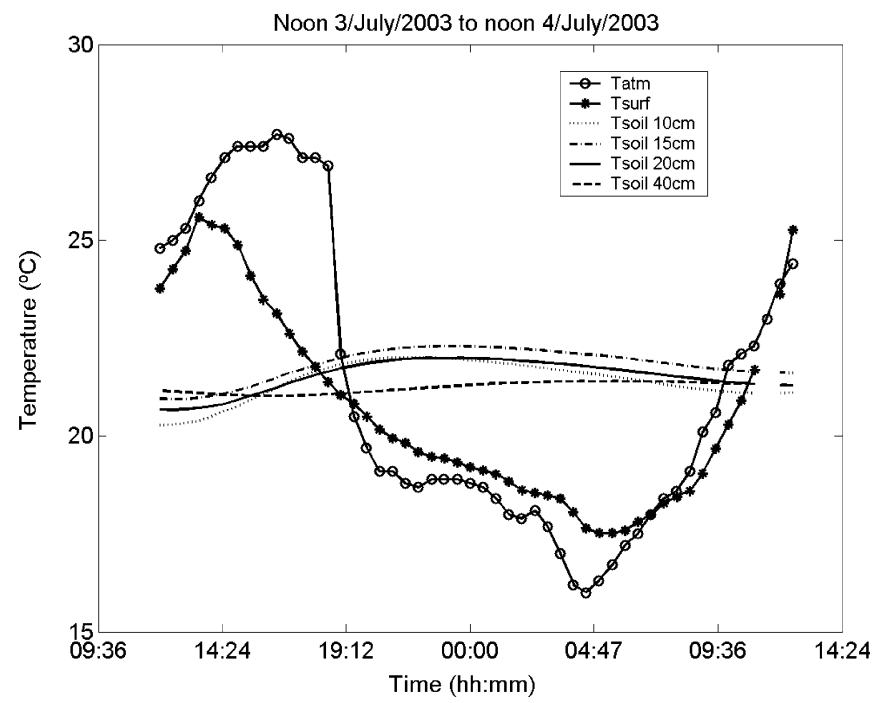

(a)

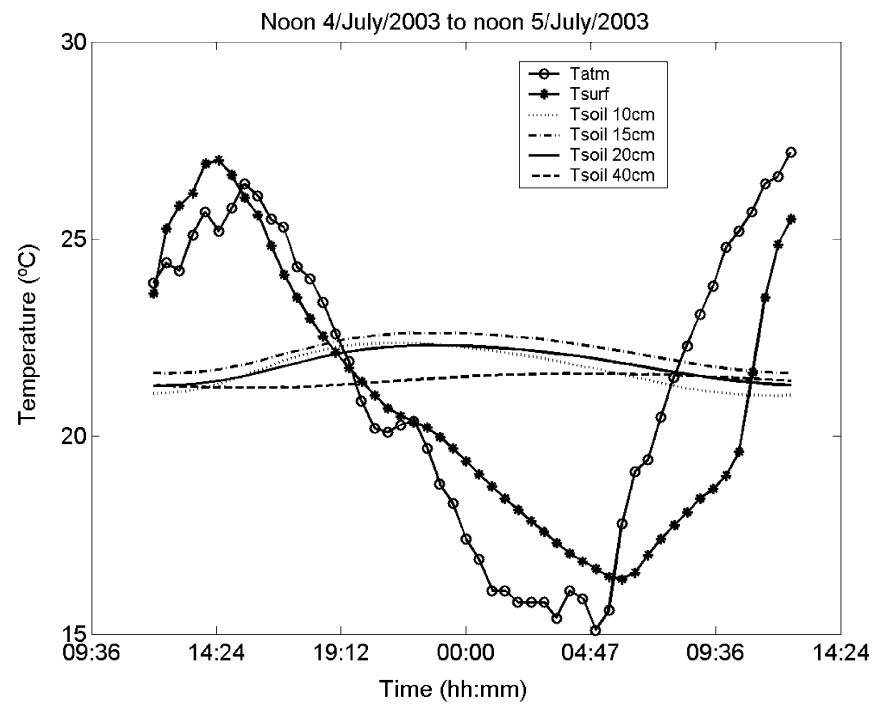

(b)

Fig. 5. Atmospheric temperature at 2-m height and soil temperature 0, 10, 15, 20 , and $40 \mathrm{~cm}$ deep acquired for two days. (a) Day of experiment 4 , the soil surface was completely dry (b) Day of experiment 5 , the soil was wetted until saturation.

and the standard deviation of the LAI for 12 plants randomly selected in the vineyard.

The LAI of each selected plant was measured in two directions: one parallel to the rows of vines (circles/continuous lines) and the other perpendicular to them (asterisks/dashed lines). Their values for each sample are compared in Fig. 7. A mean value of $1.5 \mathrm{~m}^{2} / \mathrm{m}^{2}$ was obtained for the LAI of the vineyard. These will strongly influence the brightness temperature because of the great amount of water contained in leaves and fruits.

\section{DATA PROCESSING}

The emissivity of the bare soil pixel depends on its surface roughness $(\sigma)$, temperature $\left(T_{\text {soil }}\right)$, and moisture content $(\mathrm{SM})$. When the soil is covered by vegetation its emission is affected by the canopy layer: it attenuates the soil emission and adds

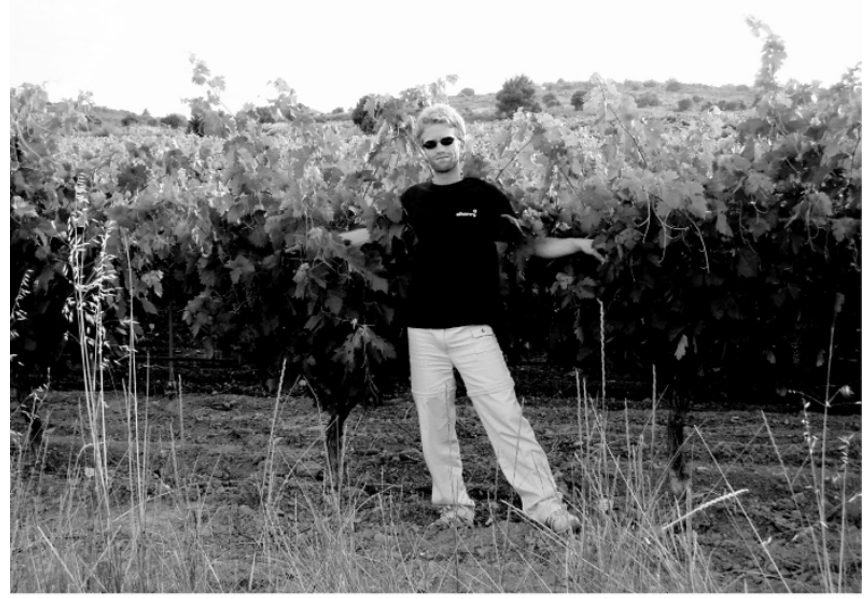

(a)

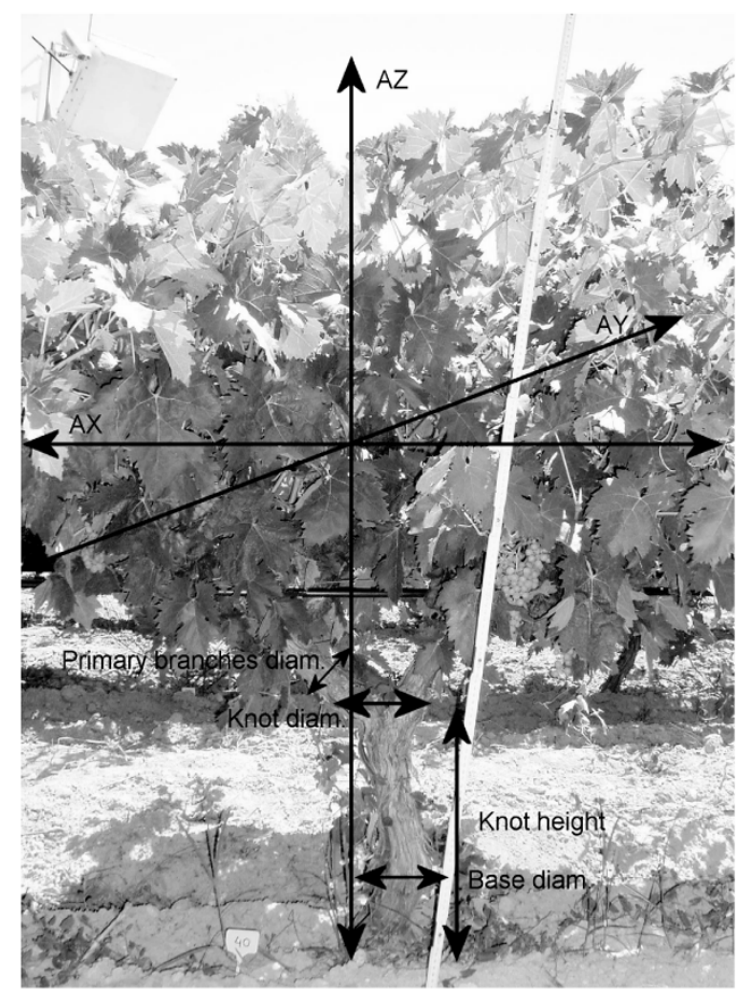

(b)

Fig. 6. (a) Grapevines under study were taller than other grapevines in the Mediterranean region. (b) Explanation of the grapevine parameters presented in Table I.

its own contribution. To model this effect, a simple radiative transfer model known as the $\tau-\omega$ model [7] has been used in this paper. This model is based on two vegetation parameters which account for the vegetation contribution to the emission: optical depth or opacity $(\tau)$, which also accounts for the attenuation, and the single scattering albedo $(\omega)$.

The $\tau-\omega$ model has been used in two different iterative retrieval algorithms: the first one is applied to obtain the opacity and albedo and the second one to retrieve the soil moisture. In both cases, a value for each sequence and look direction is obtained. 
TABLE I

GRAPEVINE CHARACTERIZATION

\begin{tabular}{lcc}
\hline Vineyard & Size $(\mathbf{c m})$ & WC (\%) \\
\hline Plant & $\mathrm{AX}=110$ to $200($ mean $=145)$ & \\
& $\mathrm{AY}=70$ to $170($ mean $=116)$ & \\
\hline Stem & Height: 37 to $180($ mean $=162)$ & \\
& $\begin{array}{c}\text { Base diameter: } 5.4 \text { to } 8.1(\text { mean }=6.62) \\
\text { Knot diameter: } 5.4 \text { to } 7.7(\text { mean }=6.9)\end{array}$ & \\
& $\begin{array}{c}\text { Diameter: } 3.7 \text { to } 4.5(\text { mean }=4.1) \\
\text { Length: } 40 \text { to } 78(\text { mean }=55.5)\end{array}$ & 10.5 \\
\hline Primary & Number: 15 to $21($ mean $=18)$ & 2.5 \\
Branches & Length: 24 to $26($ mean $=24.8)$ & \\
\hline $\begin{array}{c}\text { Secondary } \\
\text { Branches }\end{array}$ & Diameter: 0.6 to $1.2($ mean $=0.9)$ & 2.5 \\
\hline Tertiary & Diameter: 0.1 to $0.4($ mean $=0.2)$ & 16.4 \\
Branches & & 39.2 \\
\hline Leaves & $\begin{array}{c}\text { Large: } 18 \times 17-29 \times 27 \\
\text { Small: } 12 \times 11-16 \times 16\end{array}$ \\
\hline Grapes & $14 \times 5-17 \times 9$ & \\
\hline
\end{tabular}

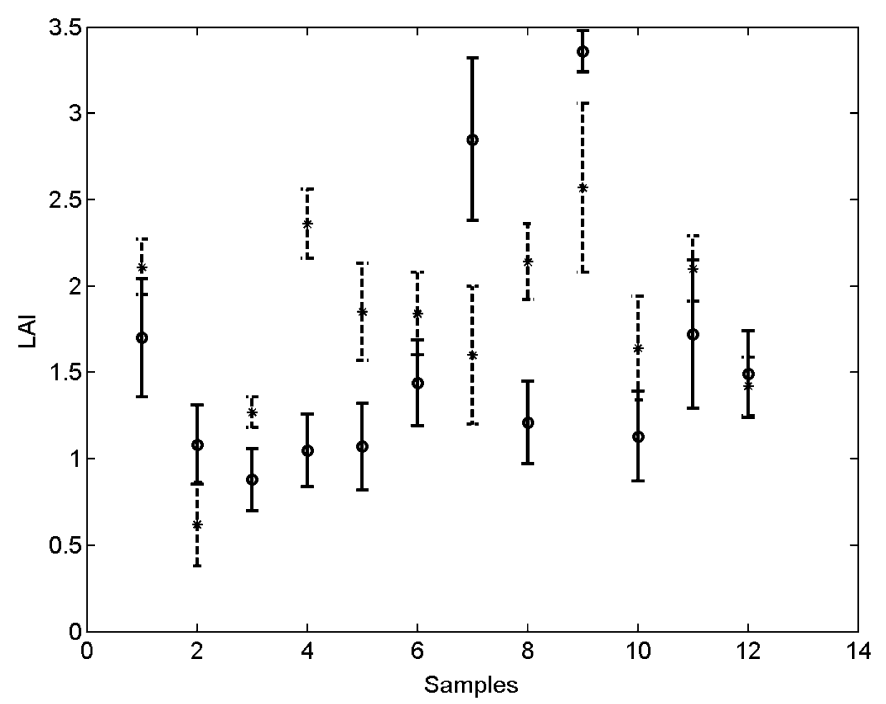

Fig. 7. Mean value (circles and asterisk) and standard deviation (continuous and dashed lines) of the measured LAI for 12 plants, randomly selected as samples. The circles with continuous lines represent the LAI of each sample plant in the direction parallel to the rows of vines, and asterisks with dashed lines represent the LAI value of each sample plant in the perpendicular direction.

\section{A. Direct Model}

The brightness temperature is estimated using an empirical expression for the complex dielectric permittivity $\left(\epsilon_{r}\right)$ of bare soils as a function of water content [8]. As the soil moisture content increases, the brightness temperature decreases because of the increment of soil reflectivity. To account for the effect of surface roughness on microwave emission, a semiempirical formula was used [9]. If the surface is not smooth, the radiometer measures higher temperature values at both polarizations and a smaller difference between the vertical $\left(T_{B v}\right)$ and horizontal $\left(T_{B h}\right)$ brightness temperatures. The effective reflection coefficient including roughness effects is given by

$$
\begin{array}{r}
\Gamma_{\text {bare }}^{p}\left(\theta, \varepsilon_{r}\right)=\left((1-Q) \cdot \Gamma_{\mathrm{spec}}^{p}\left(\theta, \varepsilon_{r}\right)\right. \\
\left.+Q \cdot \Gamma_{\mathrm{spec}}^{p}\left(\theta, \varepsilon_{r}\right)\right) e^{-4 k^{2} \sigma^{2}}
\end{array}
$$

where $k$ is the wavenumber and the cross-polarization effects are modeled by the specular soil surface reflection coefficient $\Gamma_{\mathrm{veg}}^{p}$ at $p$ polarization and the cross-polarization factor $Q$

$$
Q=0.35 \cdot\left(1-e^{-0.6 \sigma^{2} f}\right)
$$

being $f$ the electromagnetic frequency in gigahertz and $\sigma$ an empirical soil surface roughness parameter.

Once the bare soil contribution has been considered, the canopy layer is taken into account. Its contribution depends on the fraction of ground covered by vegetation and the morphology of the plants (height, density, and water content), which determine the opacity and albedo. To model the effect of vegetation on the emissivity, it is necessary to compute its dielectric properties. The dielectric constant of the vegetation involves both the complex dielectric constant of a leaf, estimated using [10], and the canopy dielectric constant, derived using the dielectric mixing model described in [11]. At $p$-polarization, the attenuation due to the canopy layer $\left(\Gamma_{\mathrm{veg}}^{p}\right)$ is related to the optical depth $\left(\tau_{p}\right)$ as follows:

$$
L_{\mathrm{veg}}^{p}=\exp \left(\frac{\tau_{p}}{\cos \theta}\right) .
$$

The contribution of the albedo $\left(\omega_{p}\right)$ is considered directly in the brightness temperature model

$$
\begin{array}{r}
T_{B p}=\frac{1-\Gamma_{\mathrm{veg}}^{p}}{1-\frac{\Gamma_{\mathrm{veg}}^{p} \Gamma_{\text {bare }}^{p}}{L_{\mathrm{veg}}^{p}}}\left[\left(1+\frac{\Gamma_{\mathrm{bare}}^{p}}{L_{\mathrm{veg}}^{p}}\right)\left(1-\frac{1}{L_{\mathrm{veg}}^{p}}\right)\left(1-\omega_{p}\right)\right. \\
\left.\cdot T_{\mathrm{veg}}+\left(1-\frac{\Gamma_{\mathrm{bare}}^{p}}{L_{\mathrm{veg}}^{p}}\right) \cdot T_{\mathrm{soil}}\right]
\end{array}
$$

where $\Gamma_{\text {bare }}^{p}$ is the reflection coefficient defined in (1), $T_{\text {veg }}$ is the vegetation temperature, $T_{\text {soil }}$ is the soil temperature (an effective temperature has been computed from the soil temperature registered at different depths, see Section II-B), $p$ stands for the polarization (horizontal or vertical), and $\Gamma_{\mathrm{veg}}^{p}$ is the reflection coefficient due to the canopy layer, which is usually very small and can be neglected, so (4) can be written as

$$
\begin{aligned}
T_{B p}=\left[\left(1+\frac{\Gamma_{\text {bare }}^{p}}{L_{\mathrm{veg}}^{p}}\right)\left(1-\frac{1}{L_{\mathrm{veg}}^{p}}\right)\left(1-\omega_{p}\right)\right. \\
\left.\cdot T_{\mathrm{veg}}+\left(1-\frac{\Gamma_{\text {bare }}^{p}}{L_{\mathrm{veg}}^{p}}\right) \cdot T_{\mathrm{soil}}\right]
\end{aligned}
$$

Some studies demonstrate that crops with vertical architecture (such as wheat) have an optical depth dependent on the polarization [12], but no study was found about vineyards. In this study, various dependences for albedo and opacity have been analyzed, obtaining the best results when the albedo and the opacity are assumed to be independent on the polarization. This fact is probably because vines do not present either a vertical or a horizontal structure. 


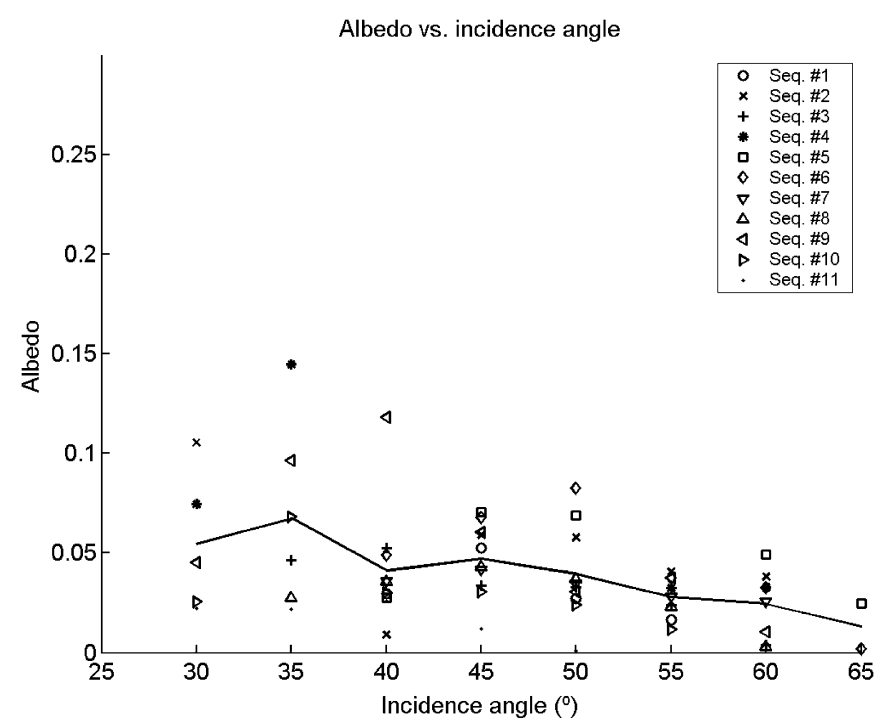

(a)

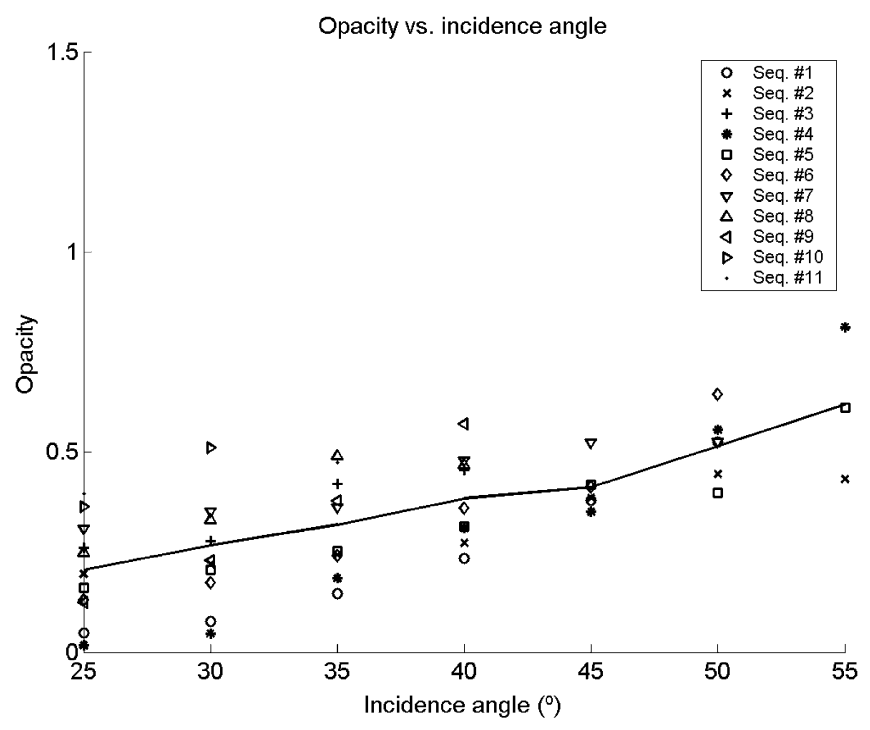

(b)

Fig. 8. (a) Albedo versus incidence angle. (b) Opacity in Nepers versus incidence angle. Dots represent the retrieved value for each sequence and all azimuth angles, and the line plots the mean value.

\section{B. Vegetation Parameters Retrieval}

Fig. 4 makes evident that in SMOS REFLEX 2003, the vegetation coverage at each pixel was dependent on the view direction of the radiometer. Therefore, the albedo and the opacity for each incidence angle and sequence have been estimated using a two parameters inverse model. Since all the radiometric measurements had the same error, this model is based on the minimization of the cost function [13]

$$
\begin{aligned}
C(\theta, \text { sequence })=\sum_{i}\left[\left(T_{B h}^{m}\left(\phi_{i}\right)-T_{B h}^{\text {data }}\left(\phi_{i}\right)\right)^{2}\right. & \\
& \left.-\left(T_{B v}^{m}\left(\phi_{i}\right)-T_{B v}^{\text {data }}\left(\phi_{i}\right)\right)^{2}\right]
\end{aligned}
$$

where $h$ and $v$ stand for horizontal and vertical polarizations, subscript $i$ indicates the seven different azimuth angles, $T_{B p}^{\text {data }}$ is the measured brightness temperature, and $T_{B p}^{m}$ is computed using the direct model, taking as input parameters the measured geophysical parameters: SM, temperature, and roughness (see

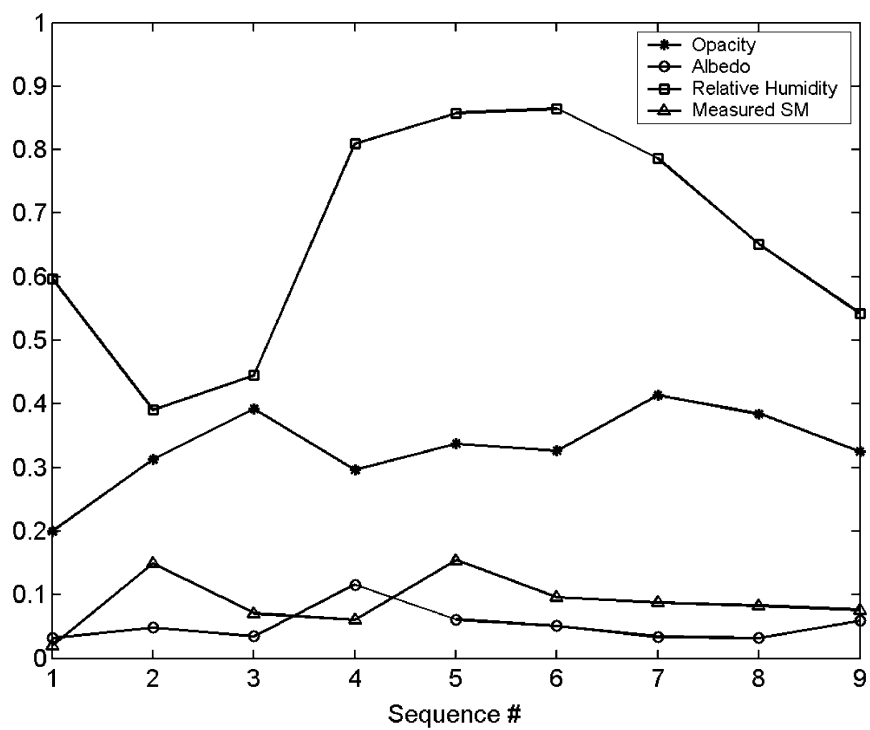

Fig. 9. Mean value of the retrieved opacity and albedo for each sequence and all incidence and azimuth angles. Mean value of the measured soil moisture and the evolution of the relative humidity are also plotted.

Section II). In order to obtain the vegetation parameters dependence on the incidence angle and sequence, measurements at different azimuth angles (from $\phi_{i}=-45^{\circ}$ to $\phi_{i}=45^{\circ}$ in $15^{\circ}$ steps) are taken as input parameters in (5). Fig. 8(a) shows the variation of the retrieved albedo respect to the incidence angle for all azimuth angles. Different symbols are used for the retrieved values at each sequence and the line plots the mean value for all the sequences at each incidence angle. The albedo takes values smaller than 0.15 , having its maximum for an incidence angle of $35^{\circ}$ and decreasing as the incidence angle increases.

Fig. 8(b) shows that the opacity tends to increase with the incidence angle, which is in accordance to the higher fraction of area covered by vegetation as the incidence angle increases [Fig. 4(a) and (b)].

On the other hand, Fig. 9 shows how the vegetation parameters depend on the day of measurement, i.e., different soil moisture, water content, and meteorological conditions. In this figure, the evolution of the measured soil moisture and the relative humidity are also plotted. Rather high values of relative humidity for a continental weather site were measured from day of experiment 4 to 9. The opacity seems to increase with the water content in the plant: an opacity increase is appreciated the day of the first irrigation, which is more evident the day after, because of the water absorption by the plant. On the fifth day, the vineyard was irrigated again, which also translates to an increment of the opacity up to the same values as for the first case.

Fig. 10 plots the emissivity obtained from LAURA's radiometric measurements versus the measured humidity at different incidence angles, for both vertical and horizontal polarizations. Each plot corresponds to a different incidence angle [from (a) $\theta_{i}=25^{\circ}$, to (f) $\theta_{i}=50^{\circ}$ ]: seven azimuth angles [from $-45^{\circ}$ to $45^{\circ}$ in steps of $15^{\circ}$ ] for the 11 days of measurements are presented. These measured values are compared with the ones obtained applying the direct model described in the above section and the measured meteorological and geophysical parameters. In this case, the retrieved albedo and opacity for each observation position have been used. Linear regressions for the two 


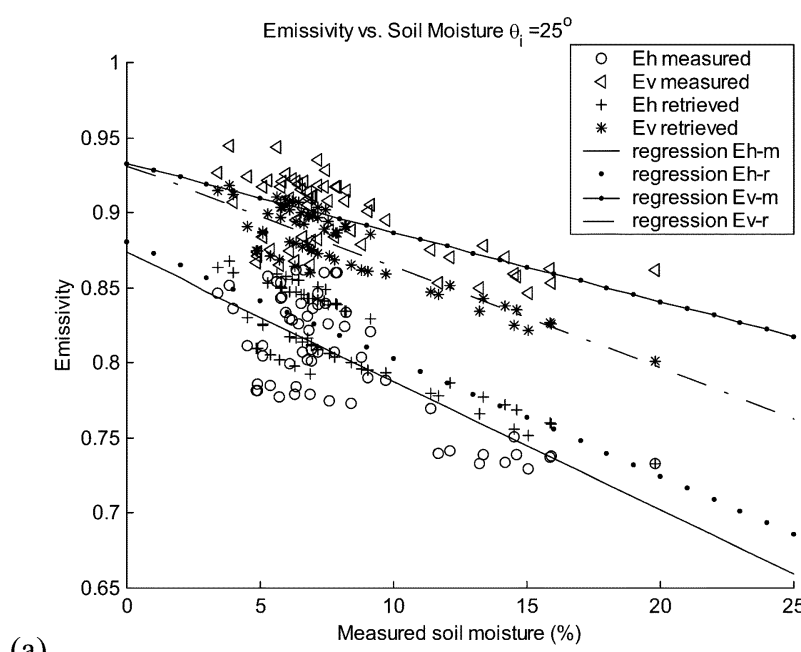

(a)

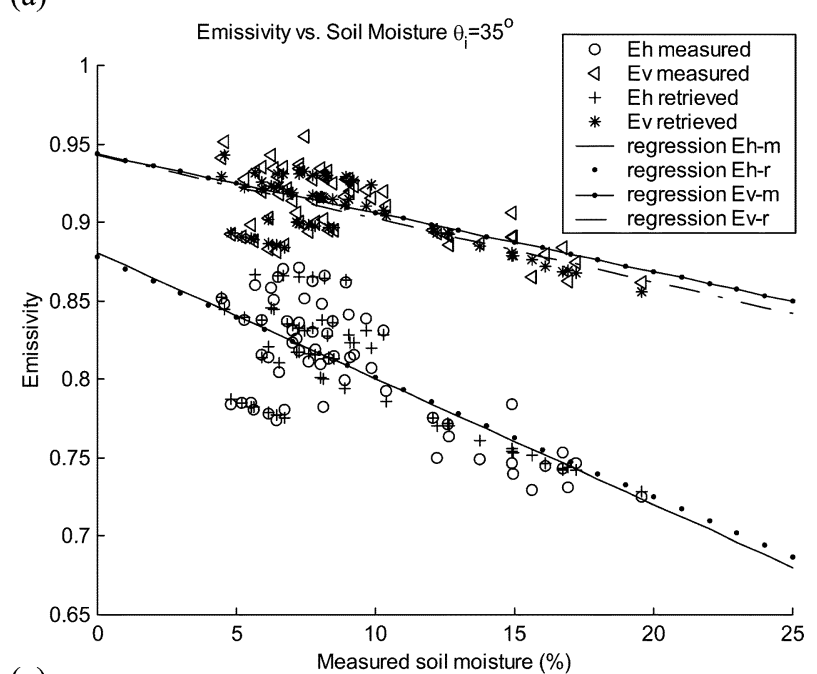

(c)

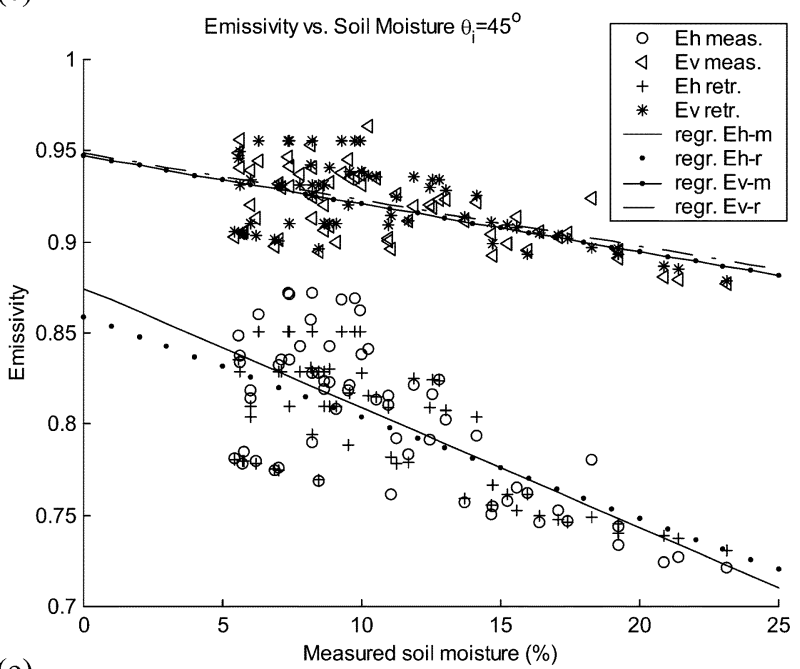

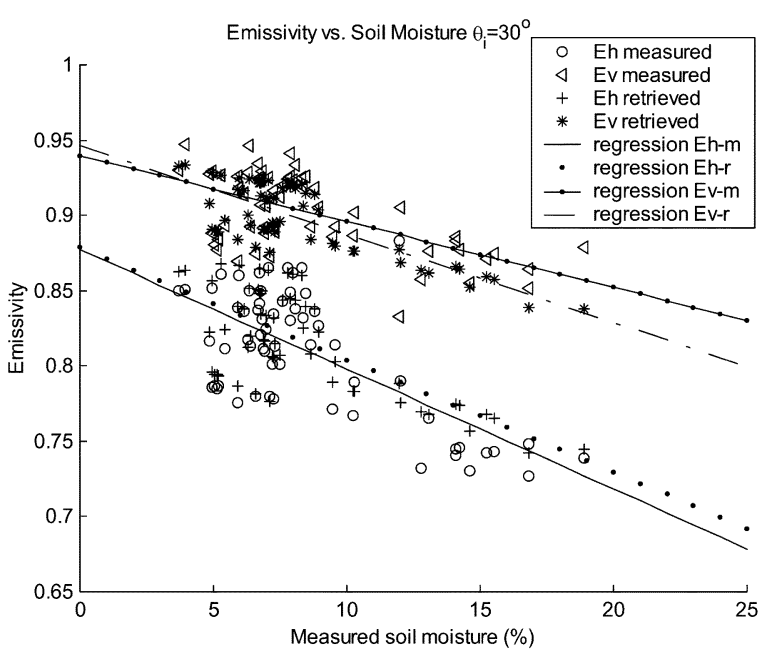

(b)

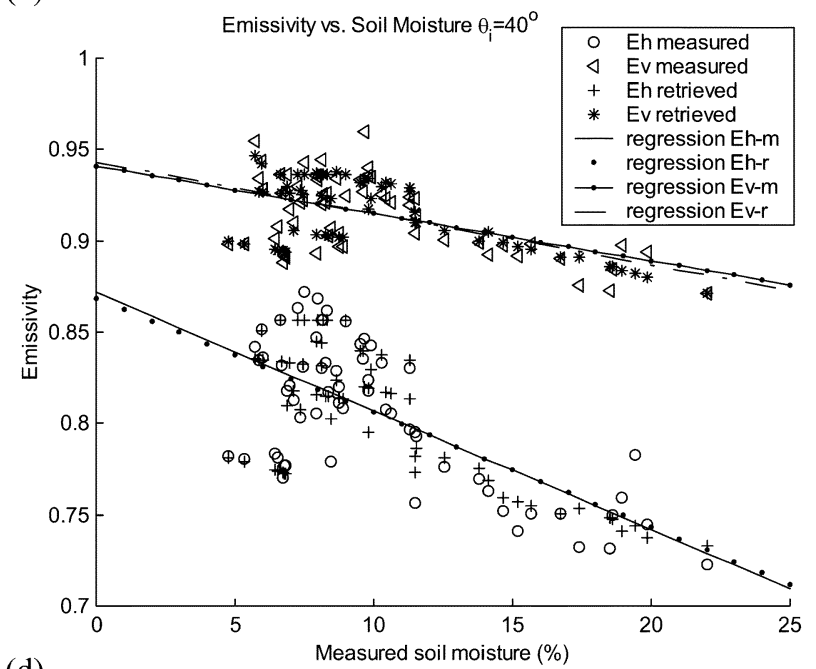

(d)

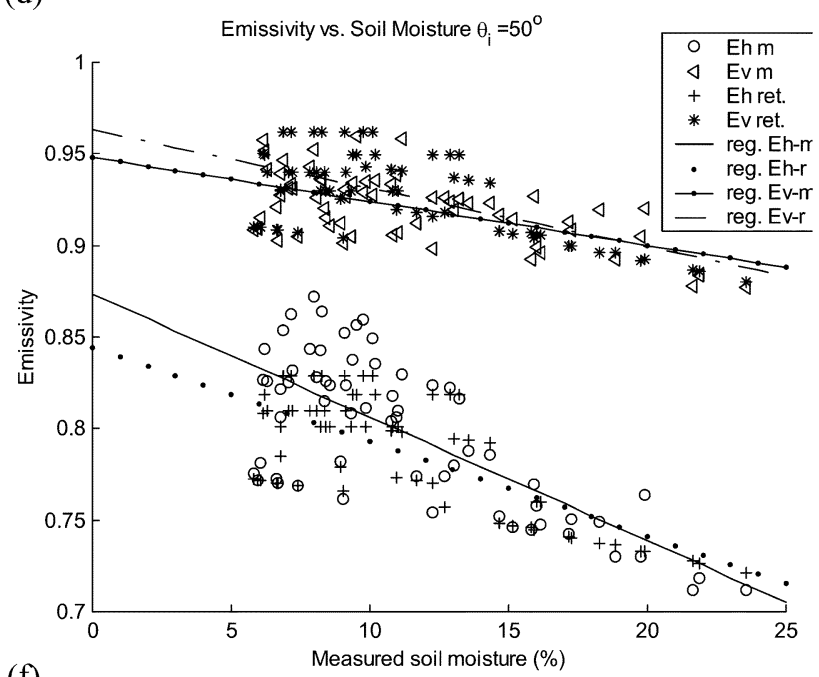

Fig. 10. Emissivity for vertical and horizontal polarizations versus measured soil moisture. Comparison between emissivity obtained with LAURA measurements (o) and the one computed with the $\tau-\omega$ model. Each plot corresponds to a different elevation angle: (a) $\theta_{i}=25^{\circ}$, (b) $\theta_{i}=30^{\circ}$, (c) $\theta_{i}=35^{\circ},(\mathrm{d}) \theta_{i}=40^{\circ},(\mathrm{e})$ $\theta_{i}=45^{\circ}$, and (f) $\theta_{i}=50^{\circ}$. Values for different days of measurement and for the seven azimuth angles (from $-45^{\circ}$ to $45^{\circ}$ ) are presented.

sets of values are also compared. Good agreement between measured and computed values is appreciated for incidence angles below $55^{\circ}$. For $\theta=55^{\circ}$, the algorithm does not always converge, and at $60^{\circ}$ and $65^{\circ}$, the convergence is rarely achieved, pointing out a problem in the emissivity model function for large incidence angles. This discrepancy can be due to the fact that as the incidence angle increases, the signal from the soil suffers from more attenuation, and scattering in the canopy is more important as well. More sophisticated models than the $\tau-\omega$ model are required. 


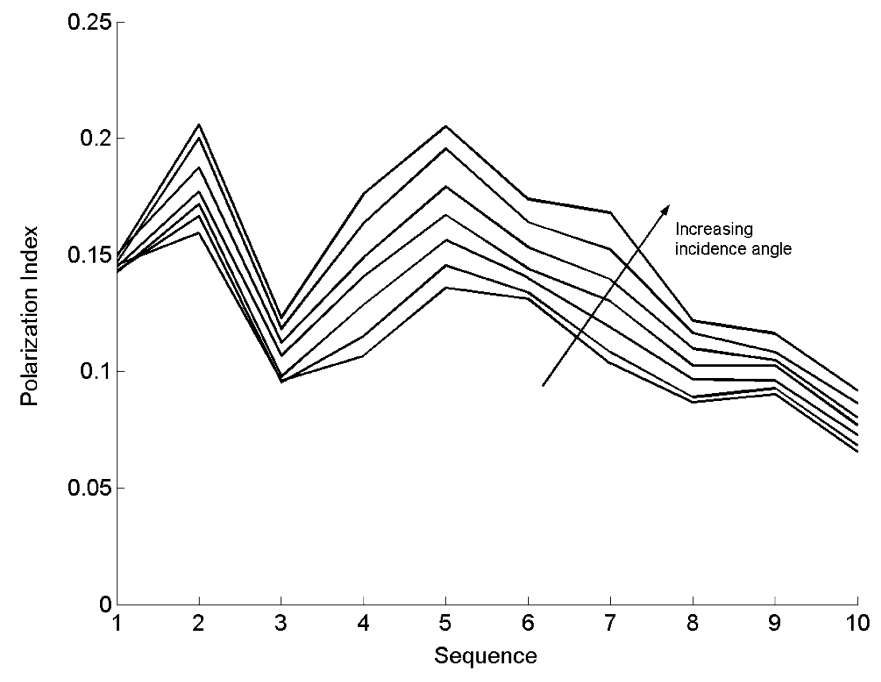

Fig. 11. Dependence of the polarization index on the incidence angle. The mean values for all azimuth angles have been presented.

\section{Polarization Index}

The polarization index $(\mathrm{PI})$ is a key parameter for monitoring vegetation [14]. For each observation position and sequence, the $\mathrm{PI}$ is computed as

$$
\mathrm{PI}=2 \frac{T_{B v}-T_{B h}}{T_{B v}+T_{B h}}
$$

Plots of PI versus sequence at each incidence angle are presented in Fig. 11. A small increment with incidence angle is appreciated. Furthermore, the PI increases when the soil is irrigated and decreases when the water has been absorbed by the plant and filtered to the soil. This behavior agrees with the results in [15]: an increment of the vegetation water content produces a decrement of the polarization index. Note that the pixels observed by the radiometer contained both bare soil (around 60\%) and soil covered by vines (around 40\%). Due to the plants covering, the PI does not only depend on SM and incidence angle, but also on the opacity and the albedo.

\section{Soil Moisture Retrieval}

In order to retrieve the SM from the radiometric measurements, an iterative algorithm, based on the least squares minimization procedure, was applied [13]. A better performance was found out when the albedo, opacity, and SM were simultaneously retrieved, instead of retrieving the soil moisture and setting the other two parameters at a fixed value. In the iterative algorithm the function to minimize is the cost function $F$

$$
\begin{aligned}
F=\left(T_{B h}^{m}-T_{B h}^{\text {data }}\right)^{2}+\left(T_{B v}^{m}-T_{B v}^{\text {data }}\right)^{2} & \\
& +\frac{\left(\tau_{r}-\tau_{i}\right)^{2}}{\sigma_{\tau}^{2}}+\frac{\left(\omega_{r}-\omega_{i}\right)^{2}}{\sigma_{\omega}^{2}} .
\end{aligned}
$$

The objective is to obtain the SM, opacity $\left(\tau_{r}\right)$, and albedo $\left(\omega_{r}\right)$ that minimize $F$. It includes two penalization terms, one for the opacity and another one for the albedo, because the first guesses for the opacity and the albedo $\left(\tau_{i}\right.$ and $\left.\omega_{i}\right)$ are the estimated values for each position of observation and sequence ob-

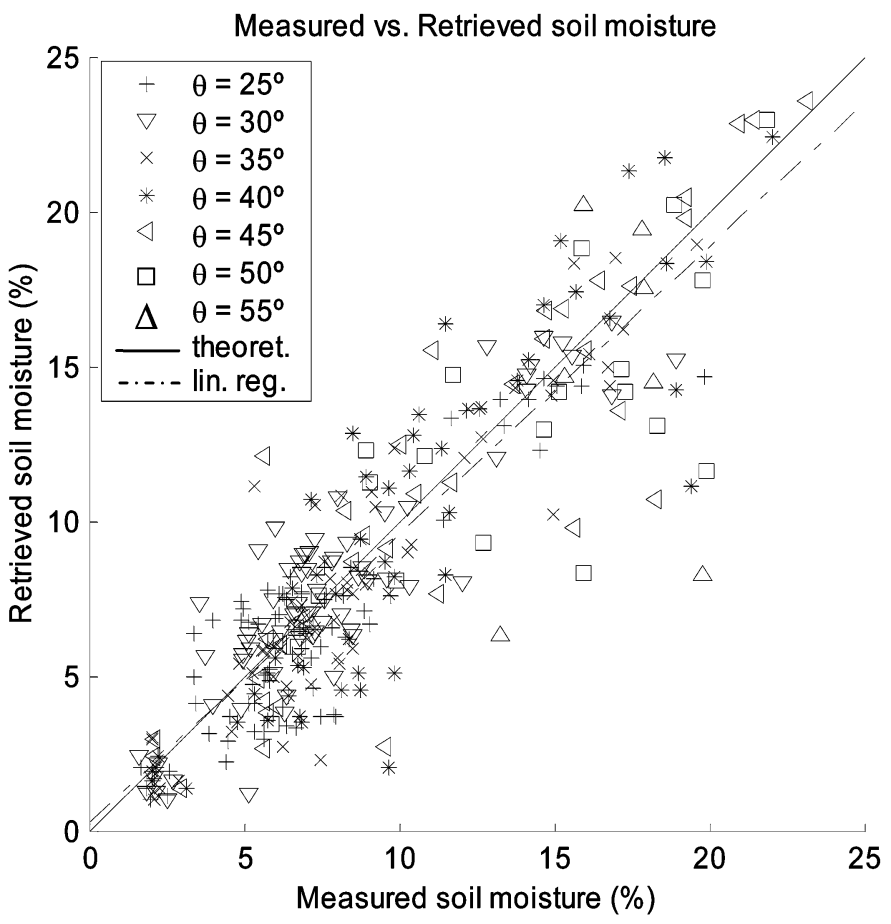

Fig. 12. Measured soil moisture versus retrieved soil moisture from LAURA measurements. Linear regression from measurements (dashed line) is close to the theoretical one (continuous line).

tained in the iterative algorithm described in Section III-B, and their values must be very close to them. The algorithm converges for incidence angles equal to or smaller than $50^{\circ}$, only for some sequences at $\theta=55^{\circ}$, and rarely for $\theta=60^{\circ}$ or $65^{\circ}$ due to the increasing discrepancy between the model and the data as the incidence angle increases. When the incidence angle increases, the canopy influence becomes more important (higher attenuation on the signal and higher scattering contribution), so a higher order approximation for the direct model becomes necessary. In Fig. 12, the retrieved and the measured SM are compared and a good agreement is appreciated: the slope of the computed linear regression is 0.9 (close to 1 ) and the ordinate at the origin is 0.29. The rms error between the data and the measurements is about $2.3 \%$, which is smaller than the $4 \%$ accuracy required for SMOS.

\section{CONCLUSION}

In this paper, a complete description of the SMOS REFLEX 2003 field campaign has been presented. A tempranillo vineyard at the València Anchor Station has been characterized for the beginning of July. During this time of the year, vines have grapes and big leaves. For this kind of plants, the opacity and albedo have been found to be independent on the polarization. A simple $\tau-\omega$ model has been used as direct model in the iterative algorithm for the retrieval of soil moisture and vegetation parameters, with good results for incidence angles up to $55^{\circ}$. For these angles, the root mean square error of the scattered points of data when the retrieved soil moisture is plotted versus the measured one is $2.3 \%$, better than the $4 \%$ required for SMOS. For incidence angles above $55^{\circ}$ the convergence of the algorithm is rarely achieved. This could be due to the larger effect of the veg- 
etation at large incidence angles, not accurately described by the simple $\tau-\omega$ model. It would be convenient to develope a higher order model for these angles.

Future field experiments such as ESA's CoSMOS are planned to fully characterize this area in other seasons, study other kinds of vegetation and the local topography, and analyze mixed-pixel effects.

\section{ACKNOWLEDGMENT}

The authors are grateful to Bodegas Iranzo for providing the opportunity of measuring their vineyard and to R. Gimenez for its support during the campaign.

\section{REFERENCES}

[1] CESBIO. (2003) Mission Objectives and Scientific Requirements of the Soil Moisture and Ocean Salinity (SMOS) Mission, Version 5. [Online]. Available: http://www.cesbio.ups-tlse.fr/data_all/pdf/ SMOS_MRD_V5.pdf.

[2] K. Saleh, J. P. Wigneron, P. Ferrazzoli, J. C. Calvet, E. López-Baeza, G. Mongiardo, and M. Pardé, "Monitoring forests from L-band microwave observations," in Proc. IGARSS, vol. 3, Toulouse, France, 2003, pp. $1628-1630$.

[3] E. López-Baeza, C. Antolín, A. Bodas, J. F. Gimeno, K. Saleh, F. Ferrer, N. Castell, C. Doménech, M. A. Sánchez, and A. Velázquez, "The Valencia anchor station: A reference cal/val area for low-resolution remote sensing data and products," presented at the 1st In. Symp. Recent Advances in Quantitative Remote Sensing, Torrent (València), Spain, Sep. $16-20,2002$.

[4] A. Camps et al., "The WISE 2000 and 2001 field experiments in support of the SMOS mission: Sea surface L-band brightness temperature observations and their application to sea surface salinity retrieval," IEEE Trans. Geosci. Remote Sens., vol. 42, no. 4, pp. 804-821, Apr. 2004.

[5] A. Camps, M. Vall-llossera, R. Villarino, J. Miranda, R. Rodríguez, R. Sabia, A. Monerris, I. Corbella, N. Duffo, and F. Torres, "The emissivity of foam-covered water surface at L-band: Theoretical modeling and experimental results from the FROG 2003 field experiment," IEEE Trans. Geosci. Remote Sens., vol. 43, no. 5, May 2005.

[6] R. Villarino, A. Camps, M. Vall-llossera, J. Miranda, and J. Arenas, "Sea foam effects on the instantaneous brightness temperature at L-band," in Proc. IGARSS, vol. 5, Toulouse, France, 2003, pp. 3076-3078.

[7] D. R. Brunfeldt and F. T. Ulaby, "Measured microwave emission and scattering in vegetation canopies," IEEE Trans. Geosci. Remote Sens., vol. GE-22, pp. 520-524, 1984.

[8] J. R. Wang and T. J. Schmugge, "An empirical model for the complex dielectric permittivity of soils as a function of water content," IEEE Trans. Geosci. Remote Sens., vol. GE-18, pp. 288-295, 1980.

[9] J. R. Wang and B. J. Choudhury, "Remote sensing of soil moisture content over bare field at $1.4 \mathrm{GHz}$ frequency," J. Geophys. Res., vol. 86, pp. 5277-5282, 1981

[10] C. Mätzler, "Microwave (1-100 GHz) dielectric model of leaves," IEEE Trans. Geosci. Remote Sens., vol. 32, no. 4, pp. 947-949, Jul. 1994.

[11] Y. Kerr and J. P. Wigneron, "Vegetation models and observations. A review," Passive Microwave Remote Sensing of Land-Atmosphere Interactions, 1995.

[12] M. Pardé, J.-P. Wigneron, A. Chanzy, P. Waldteufel, Y. Kerr, and S. Huet, "Retrieving surface soil moisture over a wheat field: Comparison of different methods," Remote Sens. Environ., vol. 87, no. 2-3, pp. 334-344, Oct. 2003.

[13] W. Press, S. Teukolsky, W. Vetterling, and B. Flannery, Numerical Recipes in C. The Art of Scientific Computing, 2nd ed. Cambridge, U.K.: Cambridge Univ. Press, 1992.

[14] S. Paloscia and P. Pampaloni, "Microwave polarization index for monitoring vegetation growth," IEEE Trans. Geosci. Remote Sens., vol. 26, no. 5, pp. 617-621, Sep. 1988.

[15] P. de Rosnay, Y. Kerr, J. C. Calvet, F. Lemaitre, M. J. Escorihuela, and J. P. Wigneron, "Retrieving surface soil moisture over a wheat field: Comparison of different methods," in Proc. Microrad, Rome, Italy, Feb. 2004, p. 42 .

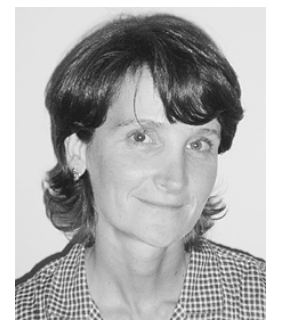

Mercè Vall-llossera (M'99) received the Senior Telecommunication Engineer and the Doctor Telecommunication Engineering degrees in 1990 and 1994, respectively, both from the Polytechnic University of Catalonia (UPC), Barcelona, Spain.

She has been lecturing and doing research at the Department of Signal Theory and Communications, UPC from 1990 until 1997 as an Assistant Professor and from 1997 until present as an Associate Professor. She spent a sabbatical year in Montreal with the scholarship of the "Programme Québécois de Bourses d'excellence" (1996-1997): "Stages de Formation postdoctorale au Québec pour jeunes diplômés étrangers.” Her research interests include numerical methods in electromagnetism, microwave radiometry, antenna analysis, and design. Currently, her research is mainly related to the study of numerical methods applied to the sea surface emissivity and their characterization at L-band and the MIRAS/SMOS project.

Dr. Vall-llossera, along with the other members of the radiometry group at UPC, was awarded the "9th Edition of the Salvà i Campillo Award" in 2004, the "Primer Premio Duran Farell de Investigación Tecnológica" in 2002, and the "Primer Premio Ciutat de Barcelona d'Investigació Tecnològica" in 2001.

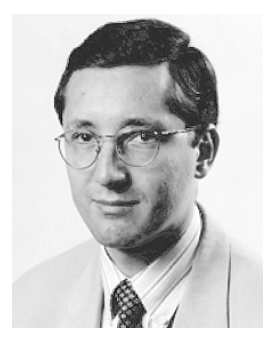

Adriano Camps (S'91-A'97-M'00-SM'02) was born in Barcelona, Spain, in 1969. He received the Telecommunications Engineering degree and the $\mathrm{Ph} . \mathrm{D}$. degree in telecommunications engineering in 1992 and 1996, respectively, both from the Polytechnic University of Catalonia (UPC), Barcelona, Spain.

From 1991 to 1992, he was with the ENS des Télécommunications de Bretagne, Bretagne, France, with an Erasmus Fellowship. In 1993, he joined the Electromagnetics and Photonics Engineering group, at the Department of Signal Theory and Communications, UPC, as an Assistant Professor, and since 1997 as an Associate Professor. In 1999, he was on sabbatical leave at the Microwave Remote Sensing Laboratory, University of Massachusetts, Amherst. His research interests are microwave remote sensing, with special emphasis in microwave radiometry by aperture synthesis techniques. He has performed numerous studies within the frame of European Space Agency SMOS Earth Explorer Mission. He is an Associate Editor of Radio Science.

Dr. Camps received the second national award of university studies in 1993, the INDRA award of the Spanish Association of Telecommunication Engineering to the best Ph.D. in 1997, the extraordinary Ph.D. award at the Universitat Politècnica de Catalunya in 1999, the First Duran Farell Award and the Ciudad de Barcelona Award, in 2000 and 2001, respectively, both for Technology Transfer, in 2002, the Research Distinction of the Generalitat de Catalunya for contributions to microwave passive remote sensing, in 2003, the Premi Nacional de Telecomunicacions (Generalitat de Catalunya) with the members of the Electromagnetics and Photonics Engineering group, and in 2004 a EURYI (European Young Investigator) Award. Also, as a member of the Microwave Radiometry Group at UPC, he received in 2000, 2001, and 2004 the 1st Duran Farell and the Ciudad de Barcelona Awards for Technology Transfeer, and the Salvà i Campillo Award of the Telecommunications (Engineering College of Catalonia) to the most innovative research project. He was Chair of $\mathrm{Cal}$ ' 01 . He is editor of the IEEE Geoscience and Remote Sensing Newsletter and President-Founder of the IEEE Geoscience and Remote Sensing Society Spain Chapter.

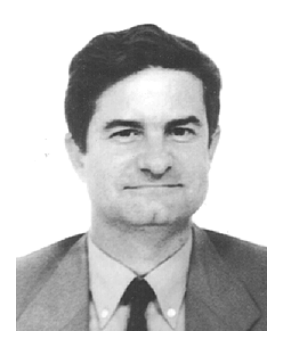

Ignasi Corbella (M'99) received the Telecommunications Engineering and Dr.Eng. degrees, both from Universitat Politècnica de Catalunya (UPC), Barcelona, Spain, in 1977 and 1983, respectively.

In 1976, he joined the School of Telecommunication Engineering in UPC as a Research Assistant in the Microwave Laboratory, where he worked on passive microwave integrated circuit design and characterization. During 1979, he worked at ThomsonCSF, Paris, France, on microwave oscillators design. In 1982, he became an Assistant Professor at UPC, an Associate Professor in 1986, and a Full Professor in 1993. He is currently teaching microwaves at the undergraduate level in UPC and has designed and taught graduate courses on nonlinear microwave circuits. During the school year 1998-1999, he worked at NOAA/Environmental Technology Laboratory, Boulder, $\mathrm{CO}$, as a Guest Researcher, developing methods for radiometer calibration and data analysis. His research work in the Department of Signal Theory and Communications, UPC includes microwave airborne and satellite radiometry and microwave system design. 


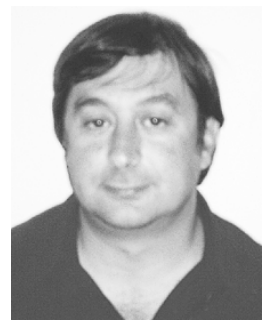

Francesc Torres (M'96) received the Ingeniero and Doctor Ingeniero degrees in telecommunication engineering from the Polytechnic University of Catalonia (UPC), Barcelona, Spain, in 1988 and 1992, respectively.

In 1988-1989, he was a Research Assistant in the RF System Division, European Space Agency, Noordwijk, The Netherlands, devoted to microwave device testing and characterization. In 1989, he joined the Antenna-Microwave-Radar group, UPC, where he is currently an Associate Professor. His main research interests are focused on the design and testing of microwave systems and subsystems. He is currently engaged in research on interferometric radiometers devoted to earth observation.

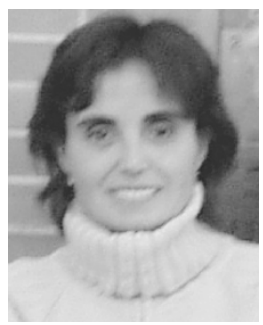

Núria Duffo (S'91-M'99) received the Telecommunication Engineer degree from the Polytechnic University of Catalonia (UPC), Barcelona, Spain, and the Doctor in Telecommunication Engineering from UPC, in 1990 and 1996, respectively.

Since 1997, she has been an Associate Professor at UPC. Her current research interests are numerical methods in electromagnetics, microwave radiometry, antenna analysis, and design.

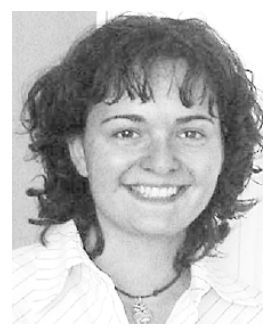

Alessandra Monerris (S'03) was born in Valencia, Spain, in 1977. She received the degree in telecommunication engineering from the Universitat Politècnica de València (UPV), Valencia, Spain, in 2001. She she is currently pursuing the Ph.D. degree at the Universitat Politècnica de Catalunya (UPC), Barcelona, Spain.

She was with the Group of Microwave Applications from UPV developing numerical methods for the electromagnetic analysis of waveguide-based devices. In 2002, she joined the Department of Signal Theory and Communications, UPC. Her main research interests deal with surface soil moisture retrieval algorithms from brightness temperature measurements.

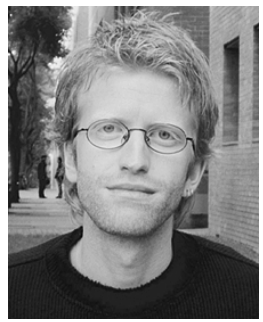

Roberto Sabia (S'03) was born in Naples, Italy, on November 13. 1975. He graduated (cum laude) in marine environmental sciences (five-year course study), curriculum in oceanography, from the Università degli Studi di Napoli "Parthenope," Naples, in 2002 . He is is currently pursuing a Ph.D. degree in signal theory and communications at the Universitat Politécnica de Catalunya (UPC), Barcelona, Spain.

In 2002, he was recipient of a grant from the Microwave Remote Sensing Laboratory , Università degli Studi di Napoli "Parthenope," on sea surface scattering models. In 2003, he joined the Department of Signal Theory and Communications, UPC. In 2003, he participated in FROG 2003 and REFLEX 2003 measurements campaigns. He is actually working on a research contract within the ESA's SMOS project. His main research interests deal with microwave radiometry and sea surface salinity retrieval.

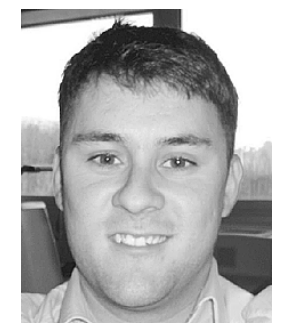

Daniel Selva was born in Palma de Mallorca, Spain, in 1980 . He received the degree in telecommunication engineering from the Universitat Politècnica de Catalunya (UPC), Barcelona, Spain, and the degree in aerospatial engineering from the Ecole $\mathrm{Na}-$ tionale Supérieure de l'Aéronautique et de l'Espace (ENSAE-SUPAERO), Toulouse, France, in 2004.

As a student, he did an internship of three months in 2003 with the Department of Signal Theory and Communications, UPC, working in the REFLEX campaign. In 2004, he joined Arianespace and is currently working on onboard sensors of the Ariane V launcher.

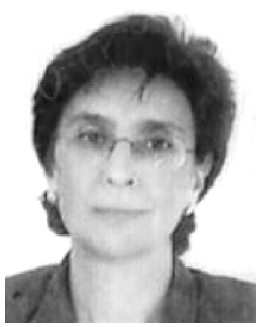

Carmen Antolín received the degree in biology science and in 1975 the Ph.D. degree from Granada University, Granada, Spain.

She was teaching at the Universitat Politècnica de València from 1975 to 1978. From 1978 until now, she has been teaching at the Universitat de València, València, Spain, teaching at the Biology, Pharmacy and Environmental Sciences schools as Associate Professor. Her research activity is related with cartography and soil evaluation in the Mediterranean area, concentrating her efforts on the analysis of the process that conducts desertification, and trying to obtain solutions to prevent them. She joined the CIDE (Desertification Research Centre) from its beginning (in 1995) and is the Director of the Territorial Planning Department. She has also been collaborating in different projects related trying to fight against desertification for the Comunidad Valenciana, such as LUCDEME. Since 2000, she has been collaborating with different European groups in projects of the European Spatial Agency, such as the EuroSTARSS 2001 campaign. Her great research activity is reflected being the lead investigator of more than 20 projects, and being coauthor of more than 30 book chapters and many articles published in different national and international magazines and conferences.

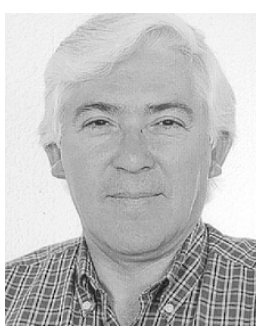

Ernesto López-Baeza has been an Associate Professor of applied physics at the University of València, València, Spain since 1987. His research interests are mainly in validation of low-resolution remote sensing data products. He is in charge of two surface validation falicities, namely the València and the Alacant Anchor Stations in Spain. He is currently involved in scientific activities of the Geostationary Earth Radiation Budget mission, the Soil Moisture and Ocean Salinity mission, and the Earth Clouds, Aerosols and Radiation Explorer mission.

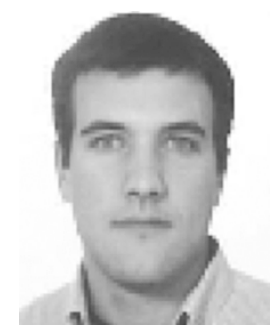

Joan Ferran Ferrer received the degree in biology and the Master degree in GIS from the University of València, València, Spain, in 1999 and 2005, respectively.

From 1999 to 2002, he worked in the CIDE (Desertification Research Centre), focussed on external and internal controls on surface's distribution of soil moisture to develop sampling strategies in remote sensing experiments. At present, he works in the application of land evaluation schemas at regional level in the north of Spain. His research interests are soil, soil scale-dependent variation, geostatistics, and mapping for land evaluation.

Kauzar Saleh, photograph and biography not available at the time of publication. 